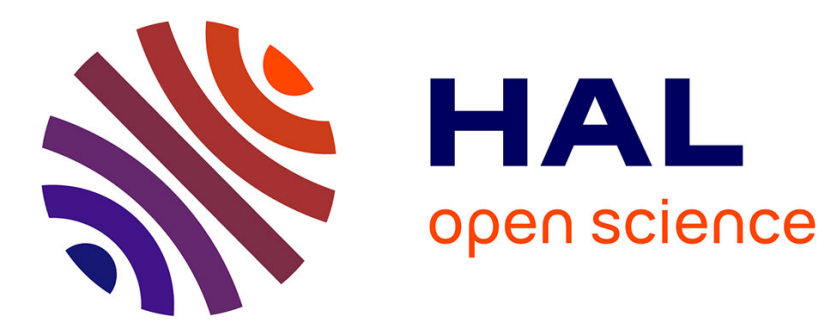

\title{
Thermodynamic calculations of stannic oxide surfaces
}

P. Mulheran, J. Harding

\section{To cite this version:}

P. Mulheran, J. Harding. Thermodynamic calculations of stannic oxide surfaces. Journal de Physique IV Proceedings, 1993, 03 (C7), pp.C7-1971-C7-1974. 10.1051/jp4:19937315 jpa-00251960

\section{HAL Id: jpa-00251960 https://hal.science/jpa-00251960}

Submitted on 1 Jan 1993

HAL is a multi-disciplinary open access archive for the deposit and dissemination of scientific research documents, whether they are published or not. The documents may come from teaching and research institutions in France or abroad, or from public or private research centers.
L'archive ouverte pluridisciplinaire HAL, est destinée au dépôt et à la diffusion de documents scientifiques de niveau recherche, publiés ou non, émanant des établissements d'enseignement et de recherche français ou étrangers, des laboratoires publics ou privés. 


\title{
Thermodynamic calculations of stannic oxide surfaces
}

\author{
P.A. MULHERAN and J.H. HARDING* \\ Dept. of Physics, University of Reading, Whiteknights, P.O. Box 220, Reading RG6 2AF, U.K. \\ *Theoretical Studies Dept., AEA Technology, Harwell Laboratory, Didcot, Oxon OX11 ORA, U.K.
}

\begin{abstract}
We estimate the free energy of ionic surfaces using an Einstein model for the phonons in the vicinity of the surface. The free energy of three of the low energy surfaces ((001), (211) and (110)) of stannic oxide is calculated.
\end{abstract}

\section{Introduction}

Many computer simulations have been performed of the surfaces of ionic crystals at zero temperature. Tasker [1] developed the MIDAS code to simulate surfaces and grain boundaries. However, these codes cannot calculate the properties of surfaces at high temperatures and such cases are often of interest. One method of calculating the properties of systems at high temperatures is to use molecular dynamics. This has been done for the case of $\mathrm{KCl}$ [2]. Another approach is to use the quasi-harmonic approximation. A way of applying this would be to construct an isolated slab of the material and diagonalise the dynamical matrix to obtain the phonons. These could be used in the standard way to obtain the free energy. The problem here is the expense of diagonalising the large matrices involved. This would need to be done a number of times to obtain the structure of the surface at finite temperature. Moreover, much of the information obtained would be wasted. All we require for the free energy is a logarithm of a function of the frequencies, averaged over the Brillouin zone. Thus most of the detailed information about the phonons that is calculated is immediately thrown away. It seems sensible, therefore, to use a simpler approximation to the phonon spectrum, which retains the main features we require, while avoiding the necessity of large-scale matrix manipulation.

\section{Einstein methods for calculating the free energy}

A localised Einstein model has been used to calculate the energy of point defects in a metal [3]. This assumes that each atom vibrates about its mean position independent of the others. This works well for metals where all the forces are short-range, but not for ionic systems. The optic modes of ionic crystals are influenced by long-range correlations between the dipoles produced by the displacements of the charged ions. This is the Lorentz field, well known in the theory of dielectric response. Some correction for this effect must therefore be made. 


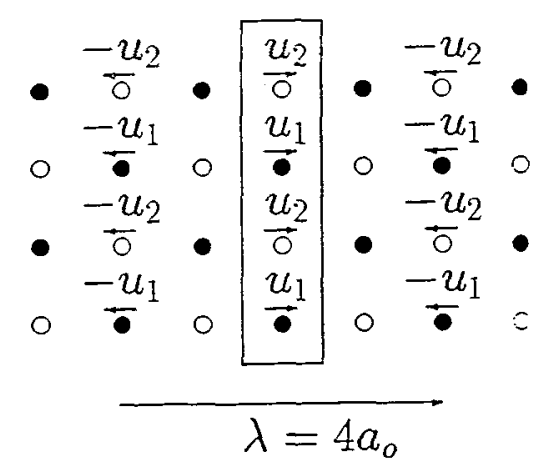

Consider the ionic vibrations in a typical phonon mode as shown above. The mode may be considered as a set of coupled layer oscillations in the direction of propagation. We can therefore obtain an estimate of the phonon frequency from the local dynamical matrix of one embedded layer. The vibrations of such a layer include acoustic and optic modes and will therefore give a good representation of the phonon density of states.

The Harwell MIDAS code has been modified [4] to include these frequencies in the energy minimisation. We consider the crystal as a stack of planes parallel to the interface. These are divided into three regions. The ions in the uppermost region are moved to minimise the free energy of the block, modelling surface relaxation. In the second region, the free energy is calculated but the ions are not allowed to move. The ions in the third region are present to ensure the correct potential field for the other ions. The convergence of the calculation can by checked by varying the region sizes.

\section{Results for stannic oxide}

We have previously studied the stability of the stannic oxide surfaces by calculating the internal energies [5] for a static lattice using the MIDAS code. The crystal structure of the oxide is such that a large number of surfaces can exist with similar energies. The static lattice calculations predict that the most stable surface is the (110) with an energy of $1.38 \mathrm{Jm}^{-2}$ and the least stable surface is the (001) with an energy of $2.37 \mathrm{Jm}^{-2}$. The shell model of Freeman and Catlow [6] was used. Experiments on thin films ([7]) support this conclusion; the (001) texture disappears on annealing. In between these extremes we found a variety of high-index surfaces. As an example of these we shall consider the (211) surface, which had an energy of $1.82 \mathrm{Jm}^{-2}$ in the static lattic approximation.

We first test the method by calculating the bulk lattice expansion and comparing with a full lattice dynamics calculation using the Harwell TYPHON code. Experimental evidence shows that the axial ratio $c_{0} / a_{0}$ does not change with temperature. We have therefore calculated the expansion by varying the bulk cell volume with respect to $a_{0}$ alone, keeping the axial ratio constant. The results are shown on the next page.

The model somewhat underestimates the expansivity, probably because the complex rutile structure can support intricate modes of oscillation that the layered model might miss. However, the agreement is adequate for our purposes. Further, we note that the calculation does not depend on the orientation of the layer we choose as the embedded layer. 


\section{$\mathrm{SnO}_{2}$ Bulk Thermal Expansion}

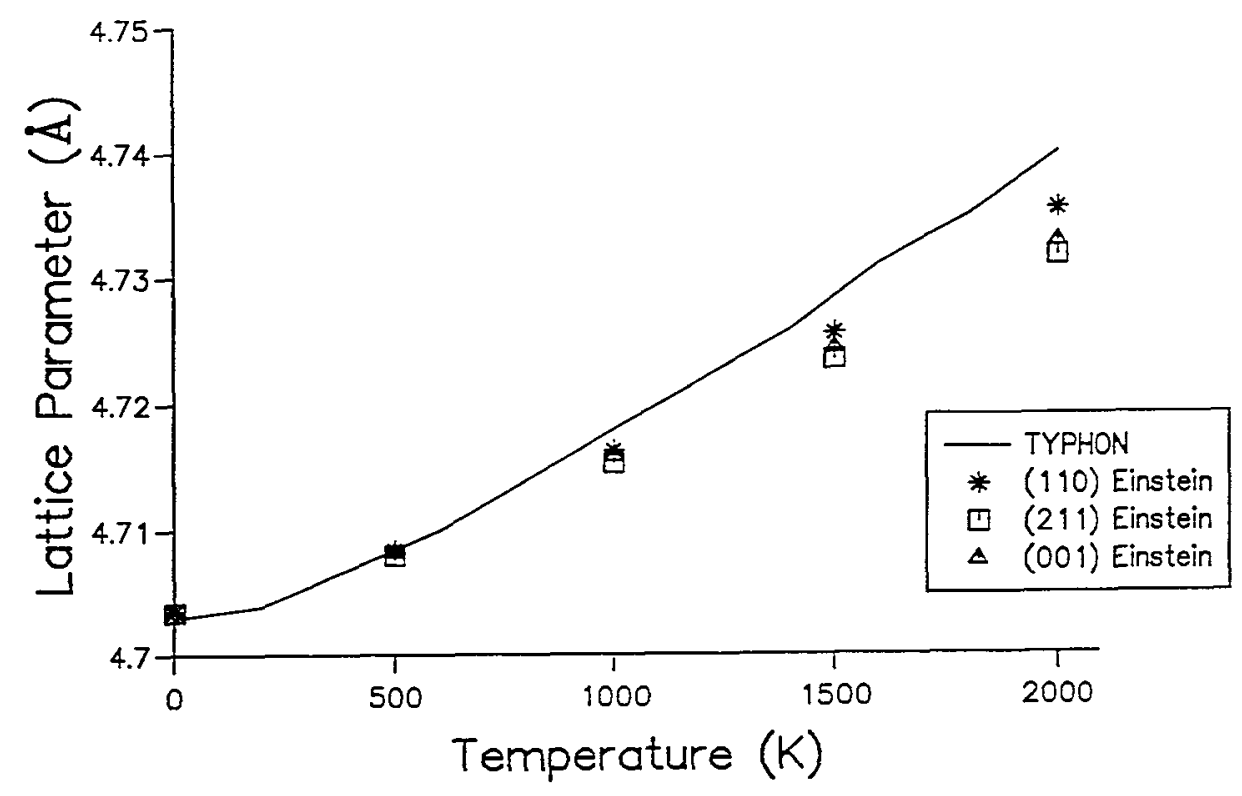

$\mathrm{SnO}_{2}$ Surface Free-energies

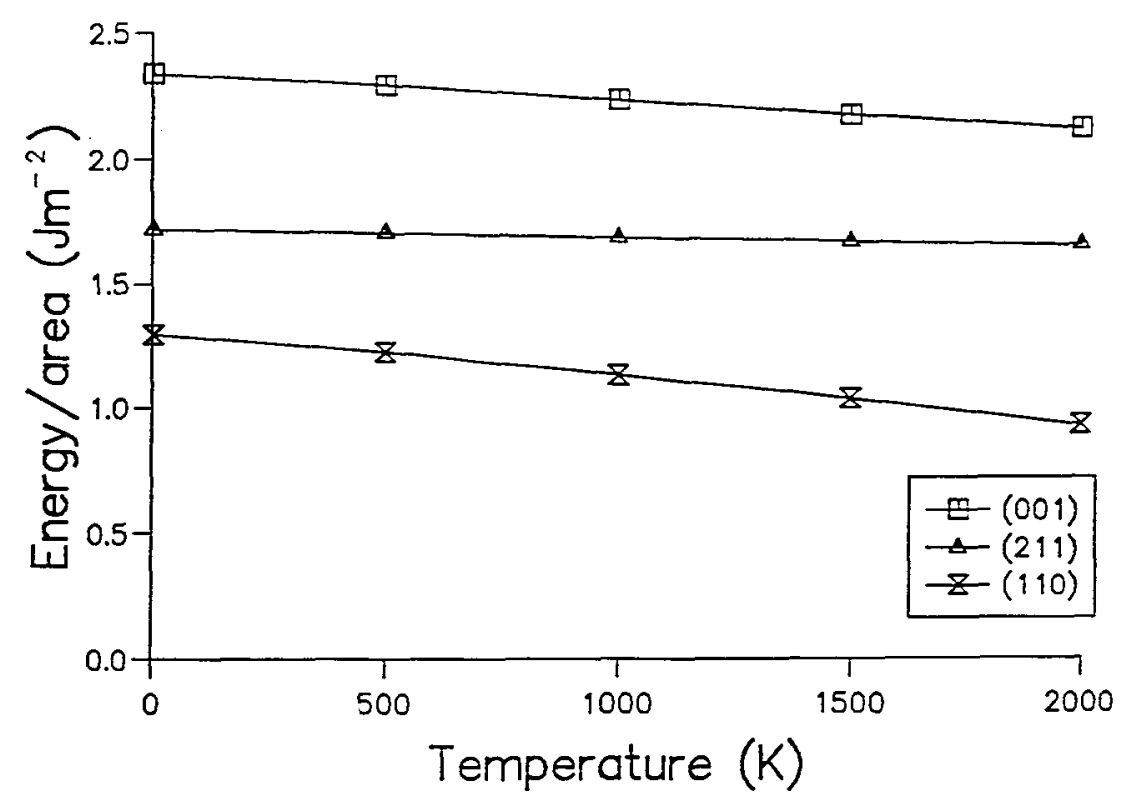


The results on the previous page show the surface energies as a function of temperature. While there is a significant variation with temperature, this is not enough to change the order of thermodynamic stability. This suggests that only reconstructions would be enough to do this. There is some evidence for this in the calculations. There is significant mode softening in some directions. This is apparently driven by the polarisability of the oxide ion. Further work, however, would probably require an improved potential model.

\section{Conclusions}

We have shown how a simplified model of the phonons can be used to study the behaviour of the surfaces of stannic oxide at high temperature. We show that the energies vary significantly with temperature. Further work on possible reconstructions and in particular the role of defects would be of interest.

\section{Acknowledgement}

This work was supported by the Corporate Research fund of AEA

\section{References}

[1 ] TASKER P.W. Phil. Mag. A39 (1979) 119.

[2] HEYES D.M., BARBER M and CLARKE J.H.R, J. Chem. Soc. (Faraday II)10(1977) 1485

[3 ] LESAR R., NAJAFABADI R. and SROLOVITZ D.J. Phys. Rev. Lett. 63 (1989) 624.

[4 ] MULHERAN P.A., Phil Mag Special issue 'Diffusion processes in transition metal oxides'; in press.

[5 ] MUlherAN P.A. and HARDING J.H., Modelling Simul. Mater. Sci. Eng. 1(1992) 39.

[6 ] FREEMAN C.M. and CATLOW C.R.A. J. Solid State Chem. 85 (1990) 65

[7 ] RASTOMJEE C.S., EGDELL R.G., GEORGIADIS G.C., LEE M.J. and TATE T.J., to be published 